\title{
Electronic combination lock system using verilog HDL
}

\author{
Nadia Mohamad Nasir ${ }^{1}$, Irni Hamiza Hamzah ${ }^{2 *}$, Azman Ab Malik ${ }^{1}$, Mohd Hanapiah Abdullah ${ }^{1}$, \\ Alhan Farhanah Abd Rahim ${ }^{1}$ and Ahmad Asri ABD Samat ${ }^{1}$ \\ Faculty of Electrical Engineering, Universiti Teknologi MARA, Cawangan Pulau Pinang, Malaysia ${ }^{1}$ \\ School of Engineering, Penang Skills Development Centre, Penang, Malaysia ${ }^{2}$
}

Received: 24-September-2020; Revised: 01-February-2021; Accepted: 05-February-2021

(C)2021 Nadia Mohamad Nasir et al. This is an open access article distributed under the Creative Commons Attribution (CC BY) License, which permits unrestricted use, distribution, and reproduction in any medium, provided the original work is properly cited.

\begin{abstract}
Recently, burglary and robbery cases has been increasing and one of the factors that contributes to the growth of these cases is the weakness on the old-style home security system. The old-fashioned key and lock system may bring challenges to the effectiveness of the system since the keys are exposed to the risks of being lost and duplicated. The advancement of technology has introduced an electronic combination lock system in which only the house owner and selected people can unlock the doors. A main goal of this paper is to design and develop an electronic combination lock system using Verilog code. The entrance door of a house will only unlock if the user slides the correct secret code on the slide switches of the Altera DE2-115 Trainer Board. A Verilog code of the keyless system had been designed and scripted in Intel Quartus Prime Software. The simulations via testbench waveforms are performed in ModelSim Software. When the system detected the entered code matched with the setting code, the door is going to unlock. Besides, when the system detected the entered code did not match the setting code, the door is still unlocked. When the user entered correct password, all green LEDs turned on and the LCD displayed "Welcome Home". Besides, when the user entered an incorrect password, all red LEDs turned on and the LCD displayed "Wrong Password". The output displayed are successfully demonstrated on the Altera DE2-115 Trainer Board according to the desired results.
\end{abstract}

\section{Keywords}

Home security system, Keyless lock system, Field programmable gate arrays (FPGA), Hardware description language (HDL).

\section{Introduction}

A study made by Wei et. al had agreed that the oldfashioned key and lock system may brought challenges to the effectiveness of the system since the keys are exposed to the risks of being lost and duplicated [1]. This feature is believed to be insecure as break-in can easily occur when the keys were duplicated [2]. The statistical analyses found that a house without a security system is more frequent to be broken-in compared to the houses that had been well-equipped with security features [3]. Normally, when an event such as intrusion occur, it presents itself arbitrarily, and there might be noticeable physical evidence is witnessed of their occurrence when completed or they pass without notice based on the purpose of the intruder [4].

\footnotetext{
*Author for correspondence
}

Therefore, this project was being inspired by the project conducted by Yeap [2] on designing the keyless lock system and continued the project to the hardware implementation. The main objective of the project proposed here is to design and develop an electronic combination lock system in order to improve the security features of a house. Nowadays, with the urbanization and miscellaneous criminal types, the efficiency of the key-and-lock has been challenged [5].

This keyless lock system is a security feature which only allows the house owner to unlock the door by sliding the secret code on the slide switches available on the Altera DE2-115 Trainer Board. The entry of the secret code was being designed by creating the code and the code length variable. For example, the secret code consists of four-digit numbers. Therefore, the house owner necessarily needed to know the accurate secret code and the code length. In order to unlock the door, the owner of the house had to insert 
a combination of the secret code on the slide switches. The door will be unlocked only when the code entered by the house owner is compatible with the setting code. Besides, the keyless lock system will activate the sleep circuit after entering invalid password for three consecutive times to indicate that the system is in a pending mode.

\section{Literature review}

The idea of the keyless lock system proposed in this project was almost similar with the project of the application of the Field Programmable Gate Arrays (FPGA) on a smart home security system conducted by Saleh et al. [6]. A smart home system designed by Saleh et al. emphasized several security features such as digital entry for automatic lock entrances and security sensors to sense the uneven movement or uncertain temperature. Both projects used the same hardware design which is Altera DE2-115 Trainer Board in order to process the password entered by the user and display of the entry status. The project designed by Saleh et al. used pushbuttons available on the Altera DE2-115 Trainer Board as the entry controller to unlock the doors. However, instead of using the pushbuttons on the FPGA as in [6], this project is going to use slide switches which were also the features available on the Altera DE2-115 Board itself. This project focused on implementing the hardware design of the lock system rather than the security sensors as designed by Saleh et. al Besides, this project extended from the project on the keyless coded home lock system [2]. The project conducted by Yeap et al. [2] only focused on the system design.

\subsection{Home security system}

Ha [7] in his study also agreed that a burglar usually tried to penetrate a private area such as a house by dodging the door lock. Based on Anitha [8] 58\% of the burglary's cases reported in USA are the aggressive break-in cases because a burglar only needs 8 to 12 minutes to break in an entry. Thus, smart home security control system has become crucial in everyday life [9].

\subsection{Field programmable gate arrays (FPGA)}

FPGA have started to take its place in new applications with their high-performance features for parallel computing and signal processing [10, 11]. The biggest advantage of using the FPGA device as a new component in the industrial environment is that the different hardware features of FPGA (flexible and reusable integrated circuit, computing parallel tasks, cost efficiency, multiple input/output capability etc.) that can be designed by a developer for different application platforms after production [12, 13]. FPGA can provide a wide opportunity for modern applications [14]. Besides, FPGA provides an impacted size and low power consumption solution [15]. FPGAs use dedicated hardware for processing logic and do not have an operating system. On the other hand, FPGA is very suitable for time-critical systems applications because every task on the FPGA hardware can utilize a different set of logic to be simultaneously run $[16,17]$. Based on a study by Rodríguez-Andina et al. [18], FPGA is one the preferred implementation platform in many industrial applications because it can support high-speed, short time-to-market, good cost-performance and availability of specialized intellectual property (IP). The FPGA is able to be programmed over two ways: straightforwardly starting with An PC utilizing the around board stage flash ROM or through the USB port [19]. A "smart home" technology is one realization of home automation ideals that employs the integrated digital systems such as FPGAs technology [6].

\subsection{Hardware description language (HDL)}

HDL may help the engineers to design a circuit logically and also functionally thus they can simulate and calculate accurately the performance of the circuit [20]. HDL is a computer-based language that had been widely used in order to describe the structure and behaviour of electronic circuits and digital logic circuits. One of the benefits of using HDL to simulate digital processing of any logical inputs is because the immediate FPGA based hardware implementation [21]. It looks like the common computer programming such as the $\mathrm{C}$ language, however HDL is specifically used to describe the structures of a hardware and the behaviour of logic circuits. In public domain, there are two standard HDLs that are supported by IEEE which were VHDL and Verilog. As for this project, the keyless lock system is being designed using Verilog coding. Verilog coding can support the logic control for production and the specification of the hardware circuitry as well as simulation and testing [22].

\section{Methods}

This project was divided into two parts which were simulation via testbench waveform and hardware implementation. There are two types of computer software used in this project which were Intel Quartus Prime Software and ModelSim Software. A hardware device used in this project is Altera DE2115 Trainer Board. 
selected. Once the START button is clicked, the configuration data will be successfully downloaded if all LEDs on the board lighted up and the progress status showed "100\% (Successful)".

\begin{tabular}{|lll|}
\hline \multicolumn{1}{|c}{ Node Name } & \multicolumn{1}{c}{ Direction } & \multicolumn{1}{c}{ Location } \\
in - CLOCK_50 & Input & PIN_Y2 \\
in - KEY[3] & Input & PIN_R24 \\
in - KEY[2] & Input & PIN_N21 \\
in - KEY[1] & Input & PIN_M21 \\
in - KEY[O] & Input & PIN_M23 \\
out LCD_BLON & Output & PIN_L6 \\
ig - LCD_DATA[7] & Bidir & PIN_M5 \\
\hline
\end{tabular}

Figure 3 Examples of assigning locations of the pins

\section{Results}

Figure 4 shows the flowchart of the keyless lock system. In order to unlock the door, the user need to enter the secret code on the slide switch on the Altera DE2-115 Trainer Board. The system will then compare the entered code with the setting code. If the entered code match with the setting code, it will proceed to the next stage which is comparing the code length of the entered code with the code length of the setting code. If the code length of the entered code matched with the code length of the setting code, the door will be unlocked. Otherwise, the attempt counter will be increased by 1 and the system will restart to allow the user to enter a new code for the second time. On the other hand, if the code length of the code entered by the user do match with the code length of the setting code, the system will start to count the number of unsuccessful attempts. If the number of unsuccessful attempts had reached more than three attempts, the system will automatically sleep. However, if the number of the unsuccessful attempts did not reach three times, the system will be reset to allow the user to enter a new code. Thus, the objective on this paper that is to introduce an electronic combination lock system to replace the old-fashioned key and lock security system had been achieved.

\subsection{Testbench modelsim}

The Verilog code of the keyless lock system is compiled and simulated in ModelSim Software. For the testbench, all the inputs and outputs have been declared in the UUT which is known as Unit Under Test [23]. This UUT needs to be instantiate in designing a testbench. This UUT acts as port mapping method which shows the connections of outputs and inputs from the main operation of
Verilog [24]. Three testbench codes were being developed to perform the functional verification on the designed Verilog code. The first testbench is to test the keyless lock system when the code entered by the user matched with the setting code while as for the second testbench is to test the designed the Verilog code when the user enter an invalid password. On the other hand, the third testbench displayed the output waveform when the user input invalid password for three consecutive attempts.

Figure 5 shows the output waveforms keyless lock system when the code entered by the user is correct. The setting code for this keyless lock system is ' 1001 '. Once the system detected the user entered ' 1001 ', the system will start to compare the code length of the entered code and the setting code. When the code length of both codes matched each other, the code length waveform goes logic ' 1 '. UNLK waveform goes high to indicate that the door is going to be unlocked. Then, logic 1 in the clear_unsuccessful will clear the number of unsuccessful attempt whereas logic 1 in clear_reset will reset the keypad pointer back to 1 respectively.

Figure 6 shows the output waveform of the keyless lock system when the user entered an invalid password. When the user entered ' 1101 ', the system detected that the entered code is not equivalent with the setting code. Therefore, the UNLK waveform is not activated indicating the door is not going to unlock. Besides, the clear_unsuccessful and clear_reset are also inactivated.

Figure 7 shows the output waveform of the keyless lock system when the user input invalid password for three consecutive times. For the first incorrect 
attempts, unsuccessful_attempt1 goes high and the second incorrect attempts will then trigger the unsuccessful_attempt2 to activate. When the user input the third incorrect password, the unsuccessful_attempt3 will go to logic ' 1 '. On the other hand, the UNLK will not activate to signify that the door is still locked. This will activate the sleep _circuit and the whole system will be in pending mode for 3 minutes. Therefore, the clear_unsuccessful and clear_reset will remain logic ' 0 ' showing the system is in sleep mode. Table 1 shows the tabulated logic of the parameters obtained in the testbench waveforms for the three different situations. Case 1 is for entering a valid password, case 2 is for entering an invalid password and case 3 is for entering invalid password for three times.

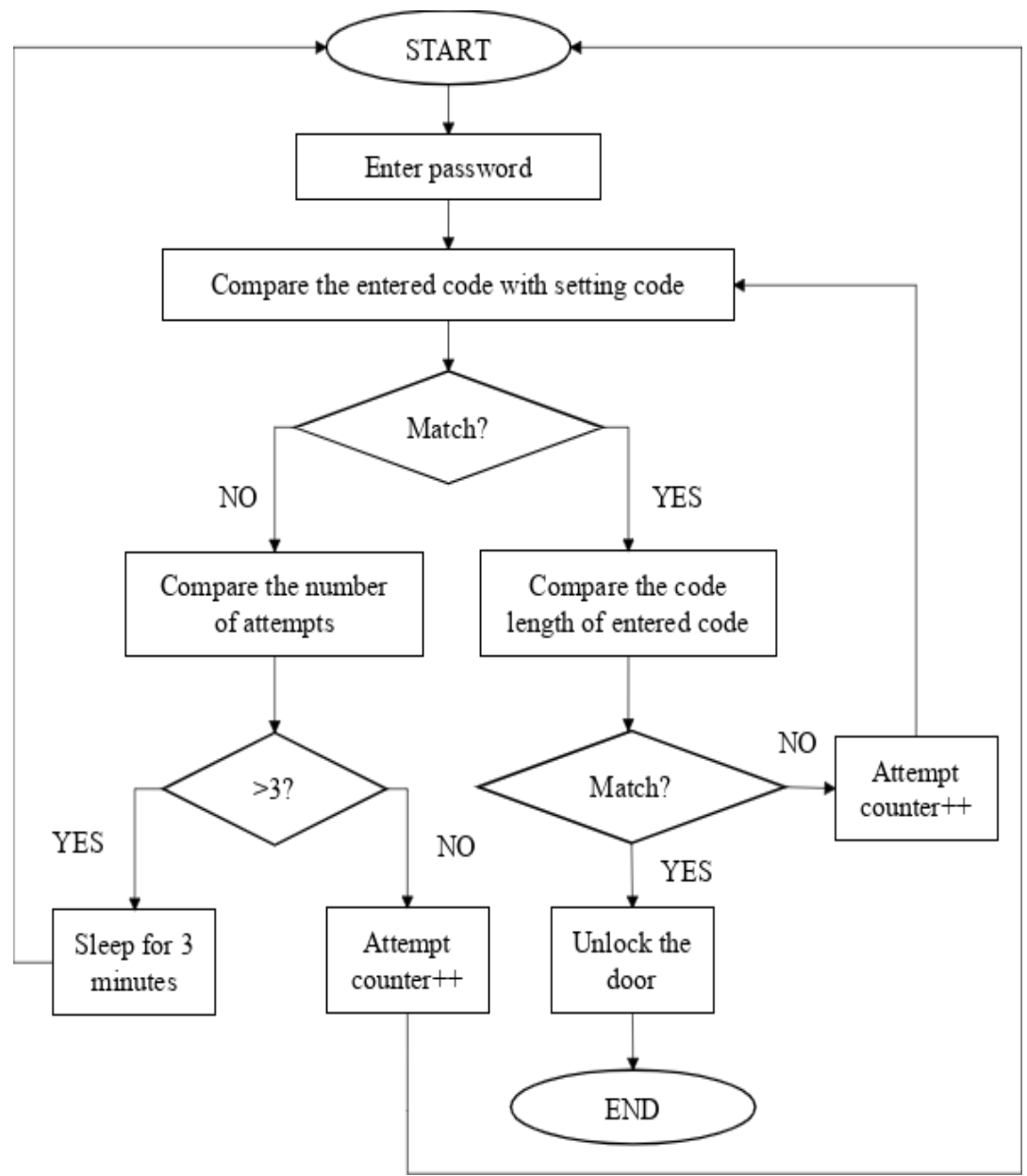

Figure 4 The flowchart of the keyless lock system
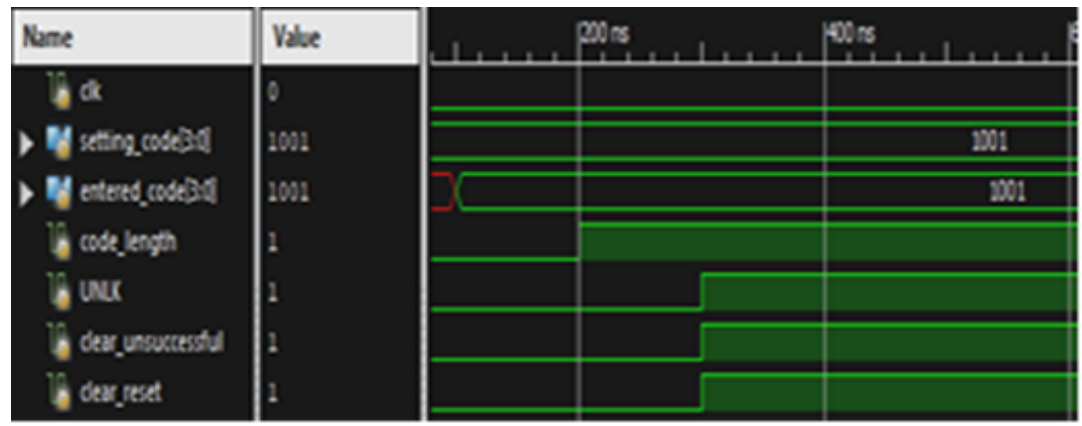

Figure 5 Output waveforms of the keyless lock system when the code entered is valid 


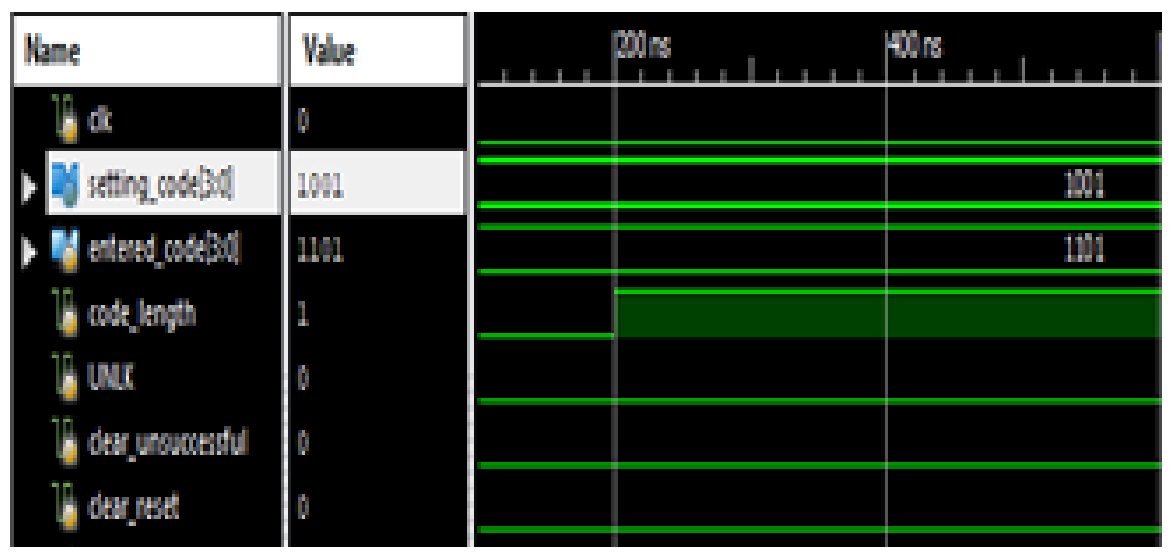

Figure 6 Output waveforms of the keyless lock system when the code entered is invalid

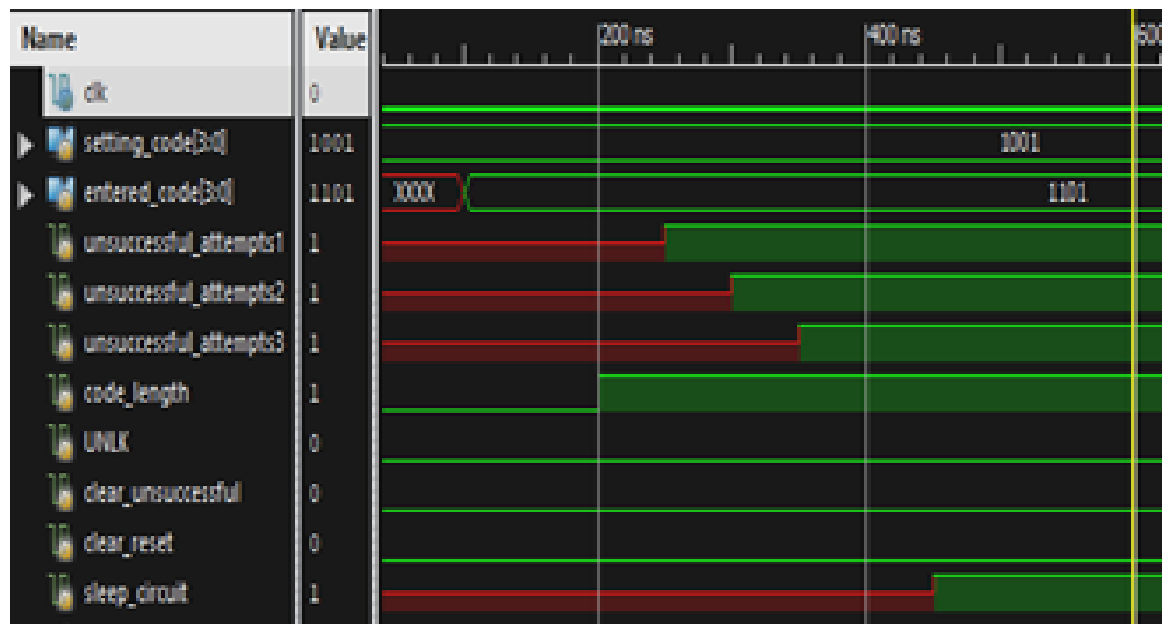

Figure 7 Output waveforms of the keyless lock system after 3 unsuccessful attempts

Table 1 The logic table of output waveforms for three different situations

\begin{tabular}{ccccccc}
\hline Case & Setting code & $\begin{array}{c}\text { Entered } \\
\text { code }\end{array}$ & $\begin{array}{c}\text { Code } \\
\text { length }\end{array}$ & UNLK & clear_unsuccessful & clear_reset \\
\hline 1 & 1001 & 1001 & 1 & 1 & 0 & 1 \\
\hline 2 & 1001 & 1101 & 1 & 0 & 0 & 0 \\
\hline 3 & 1001 & 1101 & 1 & 0 & 0 \\
\hline
\end{tabular}

\subsection{Hardware implementation}

The inputs for this system are slide switches while the outputs of the system are the greed LEDs, red LEDs and LCD display. The system begins with an initial output on the LCD display which displayed "SMART HOME" on the first line while "Enter Password" on the second line as shown in Figure 8.

In order the unlock the door, the user needs to input the password on the slide switches. The setting code that had been set for this keyless lock system is 1001 .
Once the inputs entered by the user matched with the setting code set in the Verilog code, all the green LEDs will be turned on and "Welcome Home" will be displayed on the LCD display as shown in Figure 9.

On the other hand, when the system detected that the user inputs an incorrect password on the slide switches, all red LEDs will turn on. A "Wrong Password" will be displayed on the LCD display as shown in Figure 10. 
Nadia Mohamad Nasir et al.

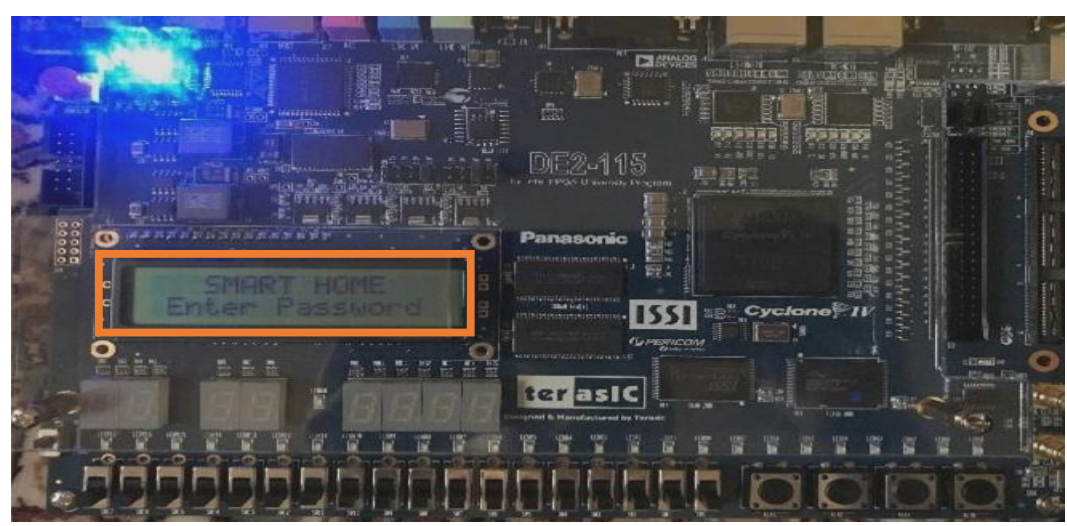

Figure 8 The initial display of the system

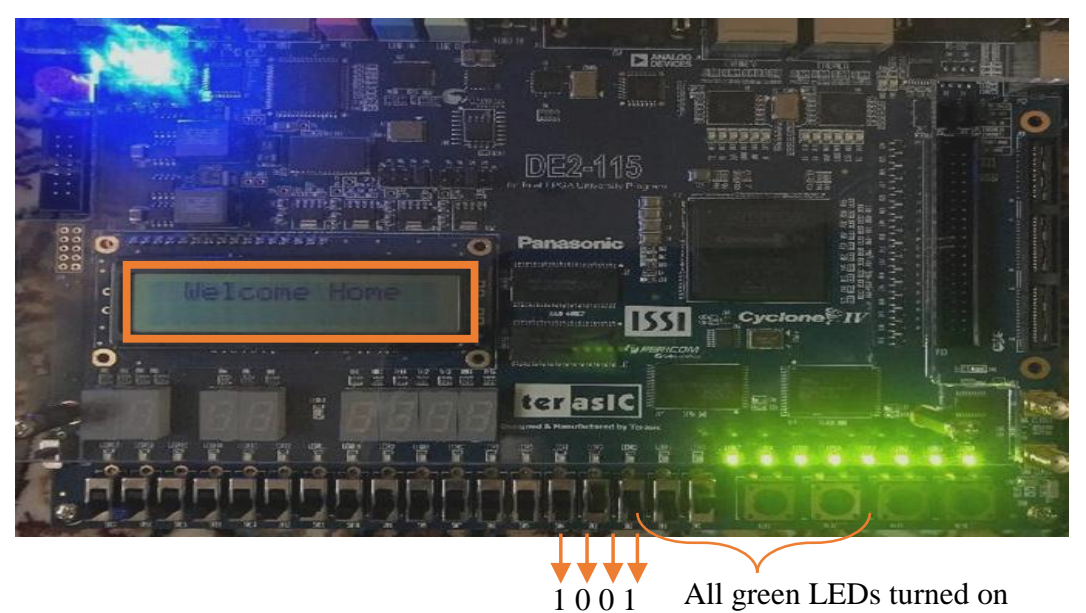

Figure 9 All green LEDs turned on

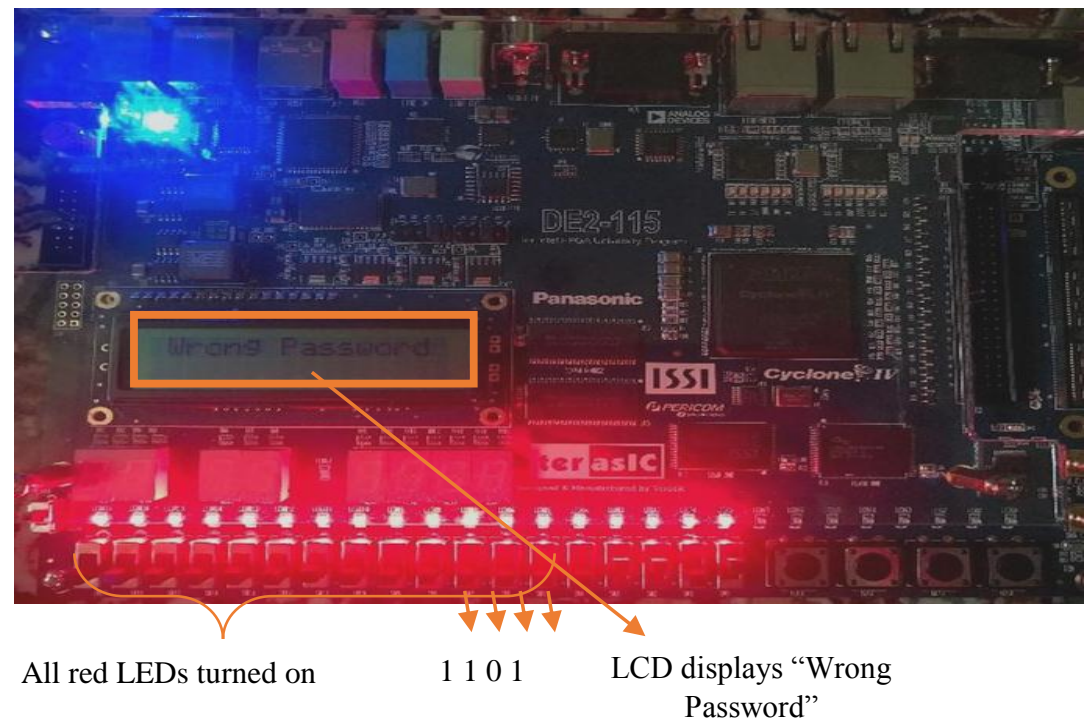

Figure 10 All red LEDs turned on 


\section{Discussion}

The study conducted by Yeap [2] also designed three different types of testbench codes for design verification. The first testbench is when the code entered by the user is correct and the second testbench is when the user entered a wrong password. The third testbench shows the output waveforms after 4 unsuccessful attempts. The first and second testbench were almost similar with the project proposed in this paper. However, the system flows of both projects were slightly different. The keyless coded home lock system designed by Yeap [2] comprises five different modules which were setup panel module, code checker module, keypad and encoder module, control unit module and sleep circuit module. Meanwhile, the electronic combination lock system designed in this paper only comprises of two modules which were lock system module and decision-making module which was the UNLK module. Most of the process of checking code, checking code length, calculating number of attempts, and sleep circuit occurred in one module only which was the lock system module. This make the keyless lock system introduced in this paper to be simpler as it may reduce the time taken to make the decision in unlocking the door.

In contradict with the electronic combination lock system proposed in this project, once the system detected that the entered code did not match with the setting code as shown in Figure 7, the whole system will stop processing immediately. The UNLK waveform will directly inactivate indicating the door was not going to unlock instead of checking the code length of the entered code as designed by Yeap [2]. Inactivation in the UNLK waveform will trigger the clear_unsuccessful and clear_reset to be inactivated. As opposed to the electronic combination lock system in which there was no reset button designed for the user to reset the system. Therefore, after the lock system detected the third unsuccessful attempt, the UNLK will automatically not activate to signify that the door is still locked. This will trigger the sleep_circuit and the whole system will be in pending mode for 3 minutes. Therefore, the clear_unsuccessful and clear_reset will remain logic ' 0 ' showing the system is in sleep mode.

A smart home system designed by Saleh et. al emphasized several security features such as digital entry for automatic lock entrances and security sensors to sense the uneven movement or uncertain temperature. The project constructed by Saleh et al. [6] used Altera DE2-115 board to process the signal transmitted from temperature sensor to FPGA board and which will then display the entry status after entering the password and activation security system on the LED seven segments displays. The entry login controller will use a push button or switches available on the FPGA board that are used to login password for the automatic doors. The electronic combination lock system designed in this paper also used the Altera DE2-115 Trainer Board in order to process the password entered by the user and display of the entry status. The project designed by Saleh et al. [6] used pushbuttons available on the Altera DE2-115 Trainer Board as the entry controller to unlock the doors. However, instead of using the pushbuttons on the FPGA, this project use slide switches which were also the features available on the Altera DE2-115 Board itself. By using slide switches, the interface will be more user-friendly as the user only need to slide the switches instead of the need to long-press the pushbuttons. Besides, this project focused on implementing the hardware design of the lock system rather than the security sensors as designed by Saleh et al. [6].

\section{Conclusion and future work}

In conclusion, an electronic combination lock system had been successfully designed using Verilog code. The output waveforms of the system had been verified and presented in ModelSim software. The output results simulated are equivalent with the designed testbench codes. The Verilog code of the keyless lock system had been implemented on the Altera DE2-115 Trainer Board. For future work, it is recommended that this project can be extended to the sound of alarm after three wrong inputs were key-in. The sound of the alarm can alert the neighbourhood that the possibility of robbery occurred in their vicinity. Then, this warning can be link directly to the owner of the house via the handphone. Therefore, the alert and trigger system will be more effective in order to educate the community to help police decreased the number of reported crime cases.

\section{Acknowledgment}

This work is sponsored by the Ministry of Higher Education (MOHE) fund from Fundamental Research Grant Scheme (FRGS) with reference no FRGS/1/2018/TK0 4/UiTM/02/35 and Universiti Teknologi MARA (UiTM) Cawangan Pulau Pinang with filing no 600-IRMI/FRGS 5/3 (156/2019). The financial support is gratefully appreciated.

\section{Conflicts of interest}

The authors have no conflicts of interest to declare. 


\section{References}

[1] Li W, Li H, Gong A, Ou Y, Li M. An intelligent electronic lock for remote-control system based on the internet of things. In journal of physics: conference series 2018 (pp.1-7). IOP Publishing.

[2] Yeap KH. Design of a keyless coded home lock system using Verilog hardware description language. International Journal of Electronics, Computer and Communications Technologies. 2012; 3(1):10-16.

[3] Schiefer M. Smart home definition and security threats. In ninth international conference on IT security incident management \& IT forensics 2015 (pp. 114-8). IEEE.

[4] Jadaa KJ, Kamarudin LM, Ahmad RB, Hussein WN. Multi objects detection and tracking system for smart home using wireless sensor network. International Journal of Advanced Trends in Computer Science and Engineering. 2019; 8(5):2434-41.

[5] Arabahmadi R. A reversible fluorescence "ON-OFFON" sensor for sequential detection of $\mathrm{F}-$ and $\mathrm{Cu} 2+$ ions and its application as a molecular-scale logic device and security keypad lock. Journal of Coordination Chemistry. 2019; 72(5-7):1187-202.

[6] Saleh SB, Mazlan SB, Hamzah NI, Karim AZ, Zainal MS, Hamzah SA, et al. Smart home security access system using field programmable gate arrays. Indonesian Journal of Electrical Engineering and Computer Science. 2018; 11(1):152-60.

[7] Ha I. Security and usability improvement on a digital door lock system based on internet of things. International Journal of Security and its Applications. 2015; 9(8):45-54.

[8] Anitha A. Home security system using internet of things. In IOP conference series: materials science and engineering 2017 (p. 042026). IOP Publishing.

[9] Lawan MB, Tijjani I. Microcontroller based electronic digital lock with security notification. Journal of Engineering Research and Reports. 2018:1-3.

[10] Yang CH, Huang SJ. Secure color image encryption algorithm based on chaotic signals and its FPGA realization. International journal of Circuit Theory and Applications. 2018; 46(12):2444-61.

[11] Zhou R, Briones J, Morehouse T. PUF Implementation and application for securing IoT devices. In IEEE 63rd international Midwest symposium on circuits and systems (MWSCAS) 2020 (pp. 221-4). IEEE.

[12] Ercan T, Al Azzawi AK. Design of an FPGA-based intelligent gateway for industrial IoT. International Journal of Advanced Trends in Computer Science and Engineering. 2019; 8(1-2):126-30.

[13] Wang MS, Zhang ZR. FPGA implementation of HOG based multi-scale pedestrian detection. In international conference on applied system invention (ICASI) 2018 (pp. 1099-102). IEEE.

[14] Schkufza E, Wei M, Rossbach CJ. Just-in-time compilation for verilog. In Architectural Support for Programming Languages and Operating Systems 2019:1-13.
[15] Karunanayake N, Gnanasekera M, Kodikara N. A robust algorithm for retinal blood vessel extraction. International Journal of Innovative Research in Computer and Communication Engineering. 2015; 3(9):7921-9.

[16] Rana KP, Kumar V, Mittra N, Pramanik N. Implementation of fractional order integrator/differentiator on field programmable gate array. Alexandria Engineering Journal. 2016; 55(2): $1765-73$

[17] Adiono T, Prakoso KS, Putratama CD, Yuwono B, Fuada S. HOG-AdaBoost implementation for human detection employing FPGA ALTERA DE2-115. International Journal of Advanced Computer Science and Applications. 2018; 9(10):353-8.

[18] Rodríguez-Andina JJ, Valdes-Pena MD, Moure MJ. Advanced features and industrial applications of FPGAs - a review. IEEE Transactions on Industrial Informatics. 2015; 11(4):853-64.

[19] Rao, S. V. R. K., Srujana, G., Priyanka, B., Nanda, R. Effective analysis of human facial appearance using JAFFE images. International Journal of Advanced Trends in Computer Science and Engineering. 2018; 7(6):149-151.

[20] Narula MS, Singla N. FPGA implementation of image enhancement using verilog HDL. International Research Journal of Engineering and Technology (IRJET). 2018; 5(5):1794-7.

[21] Chiuchisan I, Cerlinca M, Potorac AD, Graur A. Image enhancement methods approach using verilog hardware description language. In11th international conference on development and application systems 2012 (pp. 144-8).

[22] Young S, Demmings A, Ivari NE, Legault JP, Kent KB. Verilog loop unrolling, module generation, partselect and arithmetic right shift support in odin II. In proceedings of the 30th international workshop on rapid system prototyping (RSP'19) 2019 (pp. 71-4).

[23] Larios DF, Barbancho J, Biscarri F, Monedero I. A research study for the design of a portable and configurable ground test system for the A400M Aircraft. International Journal of Aerospace Engineering. 2019; 2019:1-16.

[24] Hamzah IH, Suhaimi MS, Malik AA, Rahim AF. Design and implementation of HDL remote controller for smart home system. Indonesian Journal of Electrical Engineering and Computer Science. 2020; 20(1):117-24.

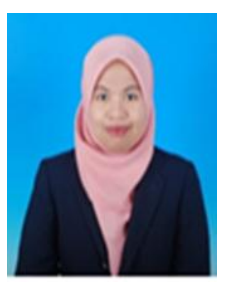

Nadia Mohamad Nasir was born in Kuala Nerang on 19th February 1997. She obtained her B. Eng (Hons) in Electrical and Electronic Engineering in 2020, from School of Electrical Engineering, Universiti Teknologi MARA, Penang Branch Campus. She is currently a Graduate Trainee Engineer in Product Enablement Solution Group Department in Intel Microelectronics Sdn. Bhd. Her research interest is in Electronic Combination Lock System using Verilog 
Coding. She is a registered Board of Engineers Malaysia (BEM) Professional Engineer.

Email: nadianaasir@gmail.com

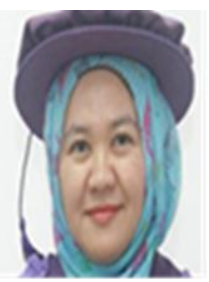

Irni Hamiza Hamzah was born in Machang, Kelantan on 6th December 1974. She obtained her B. Eng (Hons) in Electrical and Electronic Engineering in 1998, MSc. Electronics System and Design Engineering in 2005 and $\mathrm{PhD}$ in BioMEMs Sensors in 2013, which all had been obtained from School of of Electrical and Electronic Engineering, Universiti Sains Malaysia, Malaysia. She is currently a Senior Lecturer in Electronic Engineering Department, Faculty of Electrical Engineering, Universiti Teknologi MARA, Penang Branch Campus, Malaysia. Her research interests include Biosensors, BioMEMs, Neural Networks and Renewable Energy. She is a registered Board of Engineers Malaysia (BEM) Professional Engineer.

Email: irnihami@uitm.edu.my

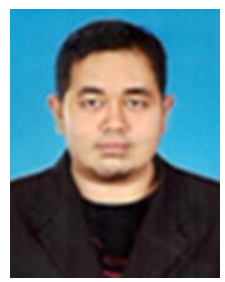

Azman Ab Malik was born in Melaka on 12 October 2018. He obtained his Diploma in Electronic Technology from KKTM Pasir Mas in 2007, Bachelor in Electrical Engineering and Technology from UNIKL BMI, Master in Electrical and Electronic Engineering from USM and Phd in Electrical Engineering from UITM. His interest in innovation towards electrical and electronic and cross multi-disciplinary area to identify a new model or method in engineering. His research interest include Electrical Power, Power System, Renewable Energy, Hybrid System, Embedded System, Wireless Power Transfer and Energy Storage. He is currently a Senior Lecturer in School of Engineering, Penang Skill Development Centre, Pulau Pinang, Malaysia. Email: azman@psdc.org.my

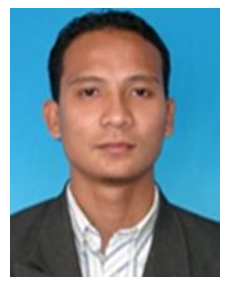

Ahmad Asri Abd Samat received a BSc. (Hons) Electrical and Electronic Engineering from MARA University of Technology, Malaysia and M. Eng (Electrical Energy and Power System from University of Malaya, Malaysia in 2004 and 2006, respectively. In 2019, he finished his $\mathrm{PhD}$ in the field of Electrical Machines and Drives from Universiti Sains Malaysia, Malaysia. Now, he is a Senior Lecturer in Electrical Engineering at the Faculty of Electrical Engineering, Universiti Teknologi MARA, Permatang Pauh Penang, Malaysia.

Email: hanapiah801@uitm.edu.my

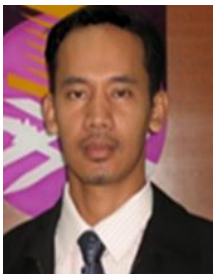

Mohd Hanapiah Abdullah received a BSc. (Hons) Electrical and Electronic Engineering from MARA University of Technology, Malaysia and M. Sc (Microelectronics) in the field of Optoelectronics from University of UKM, Malaysia in 2000 and 2005, respectively. In 2015, he finished his $\mathrm{PhD}$ in the field of Nanotechnology Device Fabrication for Green Technology from UiTM, Shah Alam, Malaysia. Now, he is a Senior Lecturer in Electronic Engineering at the School of Electronics, Faculty of Electrical Engineering, Universiti Teknologi MARA, Permatang Pauh Penang, Malaysia. $\mathrm{He}$ is a member of the NanoElectronic Center (NET), Innovation Center (IOS), UiTM Shah Alam. He is looking forward to explore new area of research and collaborations with other parties. Email: alhan570@uitm.edu.my

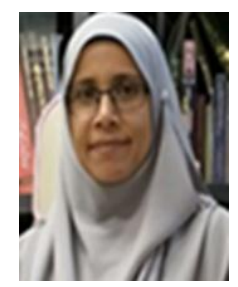

Alhan Farhanah Abd Rahim obtained her B.Eng Hons in Electronics Engineering from University of Southampton in 1998, MSc and PhD in Solid State Physics from Universiti Sains Malaysia in 2003 and 2014 respectively. She is currently senior lecturer at the Faculty of Electrical Engineering, Universiti Teknologi MARA, Malaysia. Her research interests are in synthesizing and fabricating advance semiconductor materials (group IV, III-V)) and devices utilizing low cost techniques. Her $\mathrm{PhD}$ research work entittle: Studies of Ge nanostructures Studies of Si and Ge Nanostructures Synthesized By Electrochemical and Plasma Assisted Techniques For Sensing Applications. She is author and co-author of over 20 scientific publications in this field. She is a companion member of Institute of Engineer's Malaysia (IEM) and a registered Board of Engineers Malaysia (BEM) Professional Engineer.

Email: ahmadasri759@uitm.edu.my 